\title{
MicroRNA-146a expresses in interleukin-17 producing $T$ cells in rheumatoid arthritis patients
}

\author{
Takuya Niimoto, Tomoyuki Nakasa*, Masakazu Ishikawa, Atsushi Okuhara, Bunichiro Izumi, Masataka Deie, \\ Osami Suzuki, Nobuo Adachi, Mitsuo Ochi
}

\begin{abstract}
Background: Interleukin (IL)-17 is an important factor in rheumatoid arthritis (RA) pathogenesis. MicroRNA (miRNA)s are a family of non coding RNAs and associated with human diseases including RA. The purpose of this study is to identify the miRNAs in the differentiation of $\mathrm{IL}-17$ producing cells, and analyze their expression pattern in the peripheral blood mononuclear cells (PBMC) and synovium from RA patients.

Methods: IL-17 producing cells were expanded from CD4+T cell. MiRNA microarray was performed to identify the miRNAs in the differentiation of IL-17 producing cells. Quantitative polymerase chain reaction was performed to examine the expression patterns of the identified miRNAs in the PBMC and synovium from RA and osteoarthritis (OA) patients. Double staining combining in situ hybridization and immunohistochemistry of IL-17 was performed to analyze the expression pattern of identified miRNA in the synovium.
\end{abstract}

Results: Six miRNAs, let-7a, miR-26, miR-146a/b, miR-150, and miR-155 were significantly up regulated in the IL-17 producing T cells. The expression of miR-146a and IL-17 was higher than in PBMC in the patients with low score of Larsen grade and short disease duration. MiR-146a intensely expressed in RA synovium in comparison to OA. MiR146a expressed intensely in the synovium with hyperplasia and high expression of IL-17 from the patients with high disease activity. Double staining revealed that miR-146a expressed in IL-17 expressing cells.

Conclusion: These results indicated that miR-146a was associated with IL-17 expression in the PBMC and synovium in RA patients. There is the possibility that miR-146a participates in the IL-17 expression.

\section{Background}

Rheumatoid arthritis (RA) is characterized by chronic synovial inflammation and subsequent joint destruction [1]. The infiltration of macrophages, $T$ cells and $B$ cells in RA synovium plays a crucial role in RA pathogenesis including proliferation of the lining cells, and production of inflammatory cytokines such as tumor necrosis factor(TNF-) $\alpha$, and interleukin-1- (IL-1-) $\beta$. However, the pathogenesis of RA has not been completely elucidated.

The discovery of a new linage of CD4+ effector $\mathrm{T}$ helper type17 cells (Th17cells) that selectively produce IL-17 has provided exciting new insights into immune regulation, host defense, and pathogenesis of autoimmune and other chronic inflammatory disorders including of RA [2-4]. IL-17 is a proinflammatory

\footnotetext{
* Correspondence: tnakasa@smn.enjoy.ne.jp Department of Orthopaedic Surgery, Programs for Applied Biomedicine, Division of Clinical Medical Science, Graduate School of Biomedical Sciences, 1-2-3, Kasumi, Minami-ku, Hiroshima 734-8551 Japan
}

cytokine, which induces other cytokines, such as TNF $\alpha$, IL-1 $\beta$, IL-6, IL-23 and G-CSF [5-8]. In addition, IL-17 plays a role in osteoclastogenesis via activation of RANKL(receptor activator of NF- $\kappa$ B ligand), causing bone destruction in inflammatory joints [9-11]. Several studies demonstrated that IL-17 is higher in synovial fluid, synovium and peripheral blood mononuclear cells in RA patients than that in healthy subjects [12-14]. IL-17 is recognized to be the one of the important factors in RA pathogenesis.

MicroRNA (miRNA)s are a family of $\sim 22$-nucleotide non coding RNAs identified in organisms ranging from nematodes to humans [15-17]. Many miRNAs are evolutionarily conserved across phyla, thereby regulating gene expression by posttranscriptional gene repression. The miRNAs regulate gene expression by binding the 3 '-untranslated region of their target mRNAs leading to translational repression or mRNA degradation [18-21]. Several microRNAs exhibit a tissue-specific or 
developmental stage-specific expression pattern and have been reported to be associated with human diseases such as cancer, leukemia, and viral infection $[22,23]$. These findings suggest their potential as a novel therapeutic target. miRNA might play a role in RA pathogenesis in autoimmune and other chronic inflammatory diseases including of RA. Several studies reported that miRNA might play a role in RA pathogenesis. Stancyzk et al. reported that miR-146 and miR-155 are highly expressed in RA synovial fibroblast in comparison to osteoarthritis fibroblast [24]. Nakasa et al. demonstrated that miR-146 is highly expressed in RA synovial tissue in comparison to OA and normal synovial tissue. They also revealed that miR-146 is expressed primarily in CD68+ macrophages, but also in some CD3 $+\mathrm{T}$ cell subsets and CD79a $+\mathrm{B}$ cells in RA synovial tissue [25]. Paulay et al. reported that PBMCs from RA patients exhibit statistically significant increase the expression levels of miR-146a, miR155 , miR-132, and miR-16 in comparison to healthy and disease control individuals. They also demonstrated that high levels of miR-146a and miR-16 expression correlate with active disease, whereas low expression levels correlate with inactive disease [26]. Changsheng Du et al. reported that miR-326 regulates Th-17 differentiation and associated with the pathogenesis of multiple sclerosis[27]. These findings suggest that miRNA also might play a role in the expression of IL-17, and an analysis of the expression pattern of miRNAs in IL-17 producing $\mathrm{T}$ cells might lead to the development of new treatments for RA.

The purpose of this study is to identify miRNAs in the differentiation of IL -17 producing $\mathrm{T}$ cells, and to analyze their expression pattern in the RA patients. MiRNAs were identified during the differentiation of IL-17 producing $\mathrm{T}$ cells by the expansion from healthy CD4+ $\mathrm{T}$ cells using microarray analysis, and analyzed the expression pattern of the identified miRNAs in the peripheral blood mononuclear cells (PBMC) and synovium from RA and OA patients.

\section{Methods}

\section{Patients}

This clinical study was approved by the University of Hiroshima Institutional Review Board, and written permission was obtained from all patients who participated in this study. Peripheral blood was taken from 6 RA patients $(67.3 \pm 8.02$ years of age, mean \pm standard deviation $(\mathrm{SD}))$ and 6 OA patients $(75.3 \pm 5.0$ years of age, mean \pm SD) They were diagnosed according to the American Rheumatism Association Criteria for RA or OA[28]. Synovial tissue specimens were obtained at the time of total knee arthroplasty on 4 RA patients and two RA patients (RA8,RA9) were obtained at the time of synovectomy
$(67.7 \pm 10.4$ years of age, mean \pm SD). All OA synovial tissue samples were obtained by total knee arthroplasty $(74 \pm 5.1$ years of age, mean \pm SD). Patient RA3 and RA5 showed more erosive disease, with severe destruction in the large joints. They underwent total knee arthroplasty before, and they were subsequently well controlled. The disease in patients RA1, RA2 and RA4 were poorly controlled, but soft tissue swelling, juxta-articular osteopenia, and loss of joint space were observed. Patient RA6, RA7, RA10 and RA11 showed more erosive disease, with severe destruction in the large joints. RA8 and RA9 had the least erosive disease. In addition, 6 patients with knee osteoarthritis (OA) diagnosed according to typical clinical features. The demographics of the RA and OA patients are listed in Table 1.

\section{Cell isolation and expansion of IL-17 producing T cells}

This clinical study was approved by the University of Hiroshima Institutional Review Board, and written permission was obtained from all healthy volunteers who participated in this study. Human peripheral blood was collected from 5 healthy volunteers $(31.8 \pm 1.1$ years of age, mean \pm SD) into DPBS-E (5 mM: 0.5 M EDTA) drop by drop and mixed well. This mixture was loaded slowly onto Histopaque ${ }^{\diamond}$ (Sigma Chemical Co. CA) in another tube, and centrifuged at $1000 \times \mathrm{g}$ at room temperature for $10 \mathrm{~min}$. PBMC accumulated as the middle white monolayer. After the supernatant was discarded, only the white monolayer cells were aspirated and put into DPBS-E, then centrifuged at $400 \times \mathrm{g}$ at $4^{\circ} \mathrm{C}$ for $10 \mathrm{~min}$. The supernatant was discarded, DPBS-E and ammonium chloride (The cell Experts ${ }^{\mathrm{TM}}$ ) were added at the rate of 1:3, and the mixture was allowed to stand at room temperature for $10 \mathrm{~min}$. After centrifuging at $400 \times \mathrm{g}$ at $4^{\circ} \mathrm{C}$ for $10 \mathrm{~min}$, supernatant was discarded, and DPBS-E was added and mixed well. This final process was repeated several times. The remaining white cells were peripheral blood mononuclear cells (PBMC). CD4+ T cells were isolated from PBMC using auto MACS (CD4+T cell Isolation kit, Miltenyi Biotec,). IL17 producing cells were expanded from CD4+ T cells as previously described [29]. PBMC or purified CD4+ $\mathrm{T}$ cells $\left(1 \times 10^{6}\right.$ per $\left.\mathrm{ml}\right)$ were re-suspend in fresh culture medium containing requisite antibiotics and serum plus IL-2 $(100 \mathrm{u} / \mathrm{ml})$, IL $-1 \beta$, IL- 2 , IL -6 and IL -23 (R\&D Systems; $10 \mathrm{ng} / \mathrm{ml})$. The cells were cultured in 24 well plates $\left(2 \mathrm{ml}\right.$ per well) at $37^{\circ} \mathrm{C}$ for 4 days in $5 \% \mathrm{CO}_{2}$. Afterwards, IL-17 expression was confirmed with RT-PCR and ELISA, and the presence of IL-17 producing $\mathrm{T}$ cells was also confirmed (data is not shown).

\section{Tissue samples}

Three synovial tissue specimens per one patient were obtained from random sites during surgery. Each was 
Table 1 Demographic and clinical features of this study subjects

\begin{tabular}{|c|c|c|c|c|c|c|c|c|c|c|c|}
\hline \multirow[b]{2}{*}{ subject } & \multirow[b]{2}{*}{ age } & \multirow[b]{2}{*}{ sex } & \multicolumn{3}{|c|}{$\begin{array}{l}\text { disease duration Larsen grade } K / L \\
\text { score }\end{array}$} & \multirow[t]{2}{*}{$C R P$} & \multirow[t]{2}{*}{ ESR } & \multirow[b]{2}{*}{$R F$} & \multicolumn{3}{|r|}{ synovium } \\
\hline & & & (yr) & for $R A$ & for $O A$ & & & & $\begin{array}{l}\text { PBMC } \\
\text { (source) }\end{array}$ & & medication \\
\hline$\overline{\mathrm{RA} 1}$ & 76 & $\mathrm{~F}$ & 4 & 1 & & 0.53 & 45 & 209.3 & $\circ$ & & MTX, NSAIDs \\
\hline RA2 & 69 & M & 3 & II & & 0.31 & 52 & 22.9 & $\circ$ & & bucillamine, NSAIDs \\
\hline RA3 & 59 & M & 16 & V & & 3.53 & no data & 49.5 & $\circ$ & & MTX, predonisone, NSAIDs \\
\hline RA4 & 59 & $\mathrm{~F}$ & 2 & I & & 4.12 & 74 & 129.2 & $\circ$ & & salazosulfapyridine \\
\hline RA5 & 64 & M & 17 & V & & 2.57 & 48 & 65.3 & $\circ$ & & bucillamine, NSAIDs \\
\hline RA6 & 77 & $\mathrm{~F}$ & 3 & IV & & 0.16 & 66 & 160.9 & $\circ$ & $\circ$ (knee) & salazosulfapyridine \\
\hline RA7 & 63 & $\mathrm{~F}$ & 14 & IV & & 0.33 & 21 & $<6.0$ & & $\circ$ (knee) & infliximab \\
\hline RA8 & 54 & M & 3 & III & & 3.07 & no data & no data & & $\circ$ (elbow) & MTX, predonisone, NSAIDs \\
\hline RA9 & 79 & M & 5 & III & & 0.03 & 8 & 6.1 & & $\circ$ (wrist) & NSAIDs \\
\hline RA10 & 74 & $\mathrm{~F}$ & 15 & IV & & 0.33 & 27 & no data & & $\circ$ (knee) & bucillamine, NSAIDs \\
\hline RA11 & 59 & $\mathrm{~F}$ & 5 & IV & & 3.55 & 61 & 60.8 & & $\circ$ (knee) & MTX, bucillamine, predonisone, NSAIDs \\
\hline OA1 & 74 & $\mathrm{~F}$ & & & IV & & & & $\circ$ & & NSAIDs \\
\hline $\mathrm{OA} 2$ & 78 & $\mathrm{~F}$ & & & IV & & & & $\circ$ & $\circ$ (knee) & NSAIDs \\
\hline OA3 & 83 & $\mathrm{~F}$ & & & IV & & & & $\circ$ & $\circ$ (knee) & NSAIDs \\
\hline OA4 & 71 & $\mathrm{~F}$ & & & III & & & & & $\circ$ (knee) & NSAIDs \\
\hline OA5 & 76 & M & & & IV & & & & $\circ$ & & NSAIDs \\
\hline OA6 & 70 & $\mathrm{~F}$ & & & IV & & & & $\circ$ & & NSAIDs \\
\hline OA7 & 71 & $\mathrm{~F}$ & & & IV & & & & $\circ$ & & NSAIDs \\
\hline OA8 & 74 & $\mathrm{~F}$ & & & IV & & & & & $\circ$ (knee) & NSAIDs \\
\hline OA9 & 70 & $\mathrm{~F}$ & & & IV & & & & & $\circ$ (knee) & NSAIDs \\
\hline OA10 & 71 & $\mathrm{~F}$ & & & IV & & & & & $\circ$ (knee) & NSAIDs \\
\hline
\end{tabular}

RA : rheumatoid arthritis; OA : osteoarthritis; K/L : Kellgren/Lawrence; CRP : C-reactive protein; ESR : erythrocyte sediment rate; RF : rheumatoid factor; MTX : methotrexate; NSAIDs : nonsteroidal anti-inflammatory drugs;

visually inspected to minimize contamination with noninflammatory tissue. Tissues were stored at $-70^{\circ} \mathrm{C}$ until analysis. Total RNA for the PCR analysis was isolated from tissues homogenized with Trizol (Invitrogen) on ice for. The tissue specimens were fixed in $4 \%$ paraformaldehyde and paraffin-embedded for histopathological analysis.

\section{Microarray analysis}

miRNA microarrays (NCode microarray, Invitrogen) were performed for the identification of miRNA in differentiating IL-17 producing cells. The dual-color dye swap method was used to analyze differences of miRNA expression between expanded IL-17 producing cells and non-expanded cells. Five-hundred nanograms of the enriched miRNA was labeled with the NCode Rapid miRNA labeling kit (Invitrogen) and hybridized to NCode multispecies miRNA arrays as described earlier based on a loop design, balanced with respect to array, dye, and sample. The balanced design minimized sources of unwanted variation. The arrays were scanned, aligned, and median spot intensities were obtained using a GenePix 4000B scanner (Molecular Devices, Inc., Sunnyvale, CA, USA).

\section{Synthesis of complementary DNA}

One microgram of total RNA was reverse-transcribed using the QuantiTect ${ }^{\oplus}$ Reverse Transcription Kit (Qiagen, Chatsworth, CA) according to the manufacturer's protocol. The genomic DNA elimination reaction was carried out using $2 \mu \mathrm{l}$ of gDNA wipeout buffer, $1 \mu \mathrm{g}$ $(1 \mu \mathrm{l})$ template RNA and $11 \mu \mathrm{l}$ RNase-free water at $42^{\circ} \mathrm{C}$ for $2 \mathrm{~min}$. Reverse transcription was performed in $1 \mu \mathrm{l}$ quantiscript reverse transcriptase, $4 \mu$ l quantiscript $\mathrm{RT}$ buffer, $1 \mu \mathrm{l}$ RT primer mix and $14 \mu \mathrm{l}$ template RNA (the entire genomic DNA elimination reaction) at $42^{\circ} \mathrm{C}$ for $15 \mathrm{~min}$ and $95^{\circ} \mathrm{C}$ for $3 \mathrm{~min}$ and then the cDNA product was maintained at $4^{\circ} \mathrm{C}$.

\section{Quantitative (real time) PCR}

Quantitative RT-PCR assays were performed using a TaqMan miRNA assay kit (Applied Biosystems, CA, USA) for the expression of miRNAs and SYBR Green (Invitrogen) for the expression of IL-17, Foxp3, retinoid-related orphan receptor $\gamma \mathrm{t}$ (ROR $\gamma \mathrm{t})$, IL-1 receptor-associated kinase 1(IRAK1) and suppressor of cytokine signaling 1(SOCS1). Reverse transcriptase reactions of mature miRNAs contained a sample of total RNA, $50 \mathrm{nM}$ stem-loop RT primer, $10 \times$ RT buffer, $100 \mathrm{mM}$ each dNTPs, $50 \mathrm{U} / \mu \mathrm{l}$ 
MultiScribe reverse transcriptase, and $20 \mathrm{U} / \mu \mathrm{l}$ RNase inhibitor. $15 \mu$ l reactions were incubated in a thermo cycler (BioRad) for $30 \mathrm{~min}$ at $16^{\circ} \mathrm{C}, 30 \mathrm{~min}$ at $42^{\circ} \mathrm{C}, 5 \mathrm{~min}$ at $85^{\circ} \mathrm{C}$, and held at $4^{\circ} \mathrm{C}$. Real time PCR was performed using a Mini Opticon Real-time PCR System (BioRad, Hercules, $\mathrm{CA}$ ) in a $10 \mu \mathrm{l}$ PCR mixture containing $1.33 \mu \mathrm{l}$ R product, $2 \times$ TaqMan Universal PCR Master Mix, $0.2 \mu \mathrm{M}$ TaqMan probe, $15 \mu \mathrm{M}$ forward primer, and $0.7 \mu \mathrm{M}$ reverse primer. Each SYBR Green reaction was performed with $1.0 \mu$ template cDNA, $10 \mu$ S SYR Green mix, $1.5 \mu \mathrm{M}$ primer, and water to adjust the final volume to $20 \mu \mathrm{l}$. Primer sequences were: IL-17, 5'- AAG ACC TCA TTG GTG TCA CTG CT AC-3'(forward), 5' - ATC TCT CAG GGT CCT CAT TGC G-3' (reverse); Foxp3, 5'GAG AAG CTG AGT GCC ATG CA -3'(forward), 5'AGA GCC CTT GTC GGA TGA T -3'(reverse); ROR $\gamma$ t, 5' - TGA GAA GGA CAG GGA GCC AA-3'(forward), 5'CCA CAG ATT TTG CAA GGG ATC A -3' (reverse); SOCS1, 5'- GAA CTG CTT TTT CGC CCT TA -3'(forward), 5'- CTC GAA GAG GCA GTC GAA G -3' (reverse); IRAK1, 5'- GCT CTT TGC CCA TCT CTT TG -3'(forward), 5'- GCT ACC ACG CCA GGC TAA TA -3' (reverse); GAPDH, 5' - AAG AAT TGC AAG TCT ACA TAT CAC CCA AG. -3'(forward), 5'- GGT CAT GGT CAC AGA GCC ACC-3'(reverse). All reactions were incubated in a 48 well plate at $95^{\circ} \mathrm{C}$ for $10 \mathrm{~min}$, followed by 40 cycles of $95^{\circ} \mathrm{C}$ for 15 seconds, and $60^{\circ} \mathrm{C}$ for 1 min and performed in triplicate. The U18 or GAPDH gene was used as a control to normalize any differences in the total RNA levels in each sample. A threshold cycle $\left(C_{T}\right)$ was observed in the exponential phase of amplification, and quantification of relative expression levels was performed using standard curves for target genes and the endogenous control. Geometric means were used to calculate the $\Delta \Delta \mathrm{C}_{\mathrm{T}}$ (delta-delta $C_{\mathrm{T}}$ ) values and expressed as $2^{-\Delta \Delta C T}$. The value of each control sample was set at 1 and was used to calculate the fold-change of target genes.

\section{Western Blotting}

Ten $\mu$ g of the protein were separated on NuPAGE ${ }^{\oplus}$ Novex $^{\circledast}$ Bis-Tris Mini Gels (Invitrogen, Carlsband, CA) and transferred onto a nitrocellulose membrane (Invitrogen, Carlsband, CA). Mouse monoclonal antibody against a partial recombinant IRAK1 (Abnova, Taiwan) and rabbit polyclonal anti-actin antibody (Santa Cruz Biotechnology, Santa Cruz, CA) were used as primary antibodies. Anti-mouse goat IgG (MP Biomedicals, LLC, Santa Ana, CA) for IRAK1 and anti-rabbit goat IgG (MP Biomedicals, LLC, Santa Ana, CA) for actin were used for secondary antibodies. Band detection was performed using the enhanced chemiluminescence reagent, ECL Western Blotting Detection Reagents (GE Healthcare UK Ltd, Little Chalfont, Buckinghamshire).

\section{Immunohistochemistry}

Paraffin sections were deparaffinized through xylene for three changes of five minutes each, followed by graded alcohol immersions to water and phosphate buffered saline solutions, the sections were treated with the retrieval solutions (DAKO, Dakocytomation Inc.,Copinteria,CA,USA) for 20 minutes at $95^{\circ} \mathrm{C}$. Next, the sections were depleted of endogenous peroxidase by incubation with $0.3 \% \mathrm{H}_{2} \mathrm{O}_{2}$ in absolute methanol for 15 minutes. After blocking nonspecific biding with blocking reagent for 30 minutes, the sections incubated with primary antibody at appropriate dilutions for overnight at $4{ }^{\circ} \mathrm{C}$. For primary antibodies, monoclonal rabbit anti-human antibody against IL-17 (Santa Cruz Biotechnology,Inc, CA,USA). The sections were washed and incubated with biotinylated goat anti-mouse (Sigma, Saint Louis, Missouri, USA) for 1 hour at room temperature, then, washed and incubated with avidin-biotinylated horseradish peroxidase complex $(\mathrm{ABC})$ and diaminobenzidine tetrahydrochloride (DAB; Dakocytomation Inc.,Copinteria,CA), and counterstained with Mayer's hematoxylin. The negative control was prepared in the same manner except that the primary antibody was omitted.

\section{Double staining combining in situ hybridization and immunohistochemistry}

After deparaffinization, each section was fixed in $4 \%$ paraformaldehyde for 10 minutes at room temperature, washed 3 times in phosphate buffered saline (PBS) for 3 minutes, and subsequently treated with $600 \mathrm{~g}$ of proteinase $\mathrm{K}$ for 10 minutes at room temperature. After treatment in $0.2 \%$ glycine-PBS for 10 minutes, the sections were refixed in $4 \%$ paraformaldehyde for $10 \mathrm{~min}$ utes, washed 3 times in PBS for 3 minutes each, and acetylated with $0.25 \%$ acetic anhydride in $0.1 \mathrm{M}$ triethanolamine hydrochloride for 10 minutes. After washing in PBS for 30 minutes, sections were prehybridized for 1 hour at $65^{\circ} \mathrm{C}$ with prehybridization buffer (50\% formamide and 5 saline-sodium citrate [SSC]). Hybridization with DIG-labeled riboprobes of miR-146a (B-Bridge International, Mountain View, CA) was performed overnight at $65^{\circ} \mathrm{C}$ in hybridization buffer (50\% formamide, $5 \mathrm{X}$ SSC, 5X Denhardt's solution, and $250 \mathrm{~g} / \mathrm{ml}$ of Baker's yeast transfer RNA). After hybridization, sections were washed in $5 \mathrm{X} \mathrm{SSC}$ for 30 minutes at $65^{\circ} \mathrm{C}, 0.2 \mathrm{SSC}$ for 2 hours at $65^{\circ} \mathrm{C}$, and $0.2 \mathrm{X} \mathrm{SSC}$ for 5 minutes at room temperature. Blocking was performed overnight at $4^{\circ} \mathrm{C}$ with $4 \%$ horse serum and alkaline phosphatase-conjugated Fab anti-DIG antibody (Roche) in 1\% sheep serum. Staining was performed using BCIP and nitroblue tetrazolium (NBT; Roche). Thereafter, the sections were washed in PBS and then were treated for $20 \mathrm{~min}$ utes at $90^{\circ} \mathrm{C}$ with retrieval solutions (Dakocytomation Inc., Copinteria,CA). After blocking for 30 minutes, the 
sections were incubated with primary antibody of IL-17 at appropriate dilutions for 1 hour at room temperature. After washing, the sections were incubated with Alexa Fluor 594 conjugate(Invitrogen, Carlsbad, CA) for 30 minutes at room temperature, washed, and then incubated with 4, 6-diamidino-2-phenylindole (Dojindo Laboratories, Kumamoto, Japan). The negative control was prepared in the same manner, but without the primary antibody.

\section{Statistical analysis}

The Mann-Whitney U test was used to compare the gene expression between two groups. A one-way analysis of variance (ANOVA) followed by Tukey's post hoc analysis was used to compare gene expression between the three groups. P values less than 0.05 were considered to be statistically significant. All statistical analyses were performed on a personal computer using the Stat View version 5.0 statistical software package (Abacus Concepts, Berkeley, CA).

\section{Results}

\section{Six miRNAs up-regulated in IL-17 producing T cells in} microarray analysis

The microarray analysis of the expanded IL-17 producing $\mathrm{T}$ cells identified six miRNAs that were significantly up regulated during the differentiation of the IL-17 producing $\mathrm{T}$ cells(The Center for Information Biology Gene Expression Database, CIBEX; http://cibex. nig.ac.jp. CIBEX Accession : CBX133.). The six miRNAs were miR-26a (1.81 fold; $\mathrm{p}=0.029), 146 \mathrm{a}$ (1.43 fold; $\mathrm{p}=0.040), 146 \mathrm{~b}(1.80$ fold; $\mathrm{p}=0.040), 150$ (1.61 fold; $\mathrm{p}=0.040), 155$ (2.03 fold; $\mathrm{p}=0.007)$ and let-7a $(2.12$ fold; $\mathrm{p}=0.012$; Table 2 ). There was no miRNA that was significantly down regulated in the differentiation of IL17 producing $\mathrm{T}$ cells. The expression of let-7a, miR-26a, 146a,b, 150, and 155 between expanded IL-17 producing $\mathrm{T}$ cells and non-expanded cells was compared by using real-time PCR to confirm the results of microarray

Table 2 Six miRNAs up-regulated in IL-17 producing $T$ cells in microarray analysis

\begin{tabular}{lccc}
\hline & miRNA ID & Expression ratio & p value \\
\hline 6 miRNAs up-regulated & let7a & 2.119413042 & 0.01219878 \\
& hsa-miR-26a & 1.812510994 & 0.02939706 \\
& hsa-miR-146a & 1.43106906 & 0.04019598 \\
& hsa-miR-146b & 1.802918862 & 0.03959604 \\
& hsa-miR-150 & 1.605962505 & 0.04019598 \\
& hsa-miR-155 & 2.025291111 & 0.00719928
\end{tabular}

For the identification of miRNA in differentiating IL-17 producing cells, miRNA microarrays (NCode microarray, Invitrogen) were performed. Six miRNAs were significantly up regulated in the differentiation of the IL-17 producing T cells. There was no miRNA that significantly down regulated in the differentiation of IL-17 producing T cells. (The Center for Information Biology Gene Expression Database, CIBEX; http://cibex.nig.ac.jp. CIBEX Accession : CBX133.) analysis. The expression level of these six miRNAs in expanded IL-17 producing T cells was significantly higher than in CD4+ T cells. MiR-146a and miR-146b increased by a factor of six in comparison to nonexpanded cells. The expansion of miR-155 was the greatest (9-fold), and the lowest was miR-26a (Figure 1A). Real-time PCR was performed to examine the expression of the important factors in the differentiation of human Th17 cells, including Foxp3, ROR $\gamma \mathrm{t}$, IRAK1, and SOCS1. The expression level of ROR $\gamma \mathrm{t}$, and SOCS1 in expanded IL-17 producing T cells was significantly higher than in non-expanded cells, while Foxp3 in CD4 $+\mathrm{T}$ cells was strongly expressed than in expanded IL-17 producing $\mathrm{T}$ cells. There was no significant difference in the expression of IRAK1between CD4+ T cells and expanded IL-17 producing T cells (Figure 1B). However, western blotting revealed that IRAK1 was down regulated in expanded IL-17 producing $\mathrm{T}$ cells in protein level (Figure 1C).

\section{RA patient PBMCs exhibit increased expression of Let-7a,} miR-26a, 146a,b, 150, and 155

The expression pattern of the six miRNAs in PBMC form RA, OA and healthy subjects were analyzed using real-time PCR to determine whether the miRNA identified by microarrays analysis were expressed in RA patients in comparison to OA and healthy subjects,. The expression level of miR-26a, miR-146a/b, miR-150 and miR-155 in RA patients were significantly higher than in healthy subjects. However, there were no significant differences between RA and OA patients in the expression level of miR-26a, miR-146b. There were significant differences between RA and OA patients in the expression level of miR-146a, miR-150 and miR-155. There was no significant difference in the expression level of Let-7a between RA, OA patients and healthy subjects (Figure $2 A)$. Real time PCR of IL-17 was used to examine the relationship between the expression level of six miRNAs and IL-17 in RA patients. The expression level of miR146a was similar to that of IL-17. Patient RA1 and RA4 had high disease activity, although the Larsen grade was low. The expression level of miR-146a and IL-17 in patient RA1 and RA4 was high in comparison to the other patients. miR-146a expressed intensely with IL-17 expression in PBMC from the patients with early stage of RA and high disease activity (Figure 2B).

\section{The synovium from RA patients exhibit increased expression of miR-146a,b, 150, and 155}

RA pathogenesis is characterized by synovial inflammation, secretion of inflammatory cytokines including IL-17 and subsequent joint destruction. Therefore, the expression pattern of miR-146a/b, miR-150, and miR155 in the synovium of RA patients was examined using 

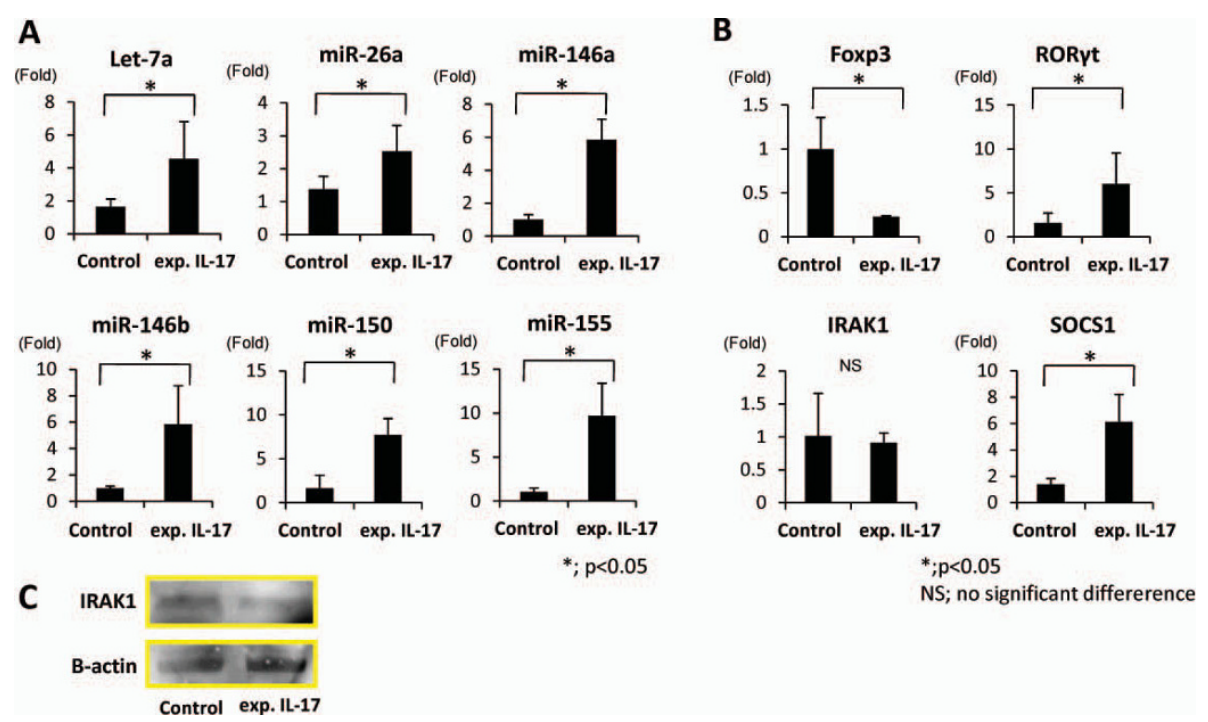

Figure 1 A quantitative PCR analysis of the expression of six miRNAs, Foxp3, ROR $\gamma t$, IRAK1, and SOCS1. A, A quantitative PCR analysis of the expression of let-7a, miR-26a, 146a,b, 150, and 155 in expanded IL-17 producing T cells and non-expanded cells. The expression level of these six miRNAs in expanded IL-17 producing T cells was significantly higher than in non-expanded cells. MiR-146a and miR-146b have increased by a factor of six in comparison to non-expanded cells. miR-155 showed a 9-fold increase, and miR-26a showed the smallest increase. B, A quantitative PCR analysis of the expression of Foxp3, RORyt, IRAK1, SOCS1. The expression level of RORyt, and SOCS1 in expanded IL-17 producing T cells significantly was higher than in non-expanded cells, while Foxp3 in expanded cells was significantly down regulated in comparison to non expanded cells. There was no significant difference in the expression of IRAK1. C,Western blotting of IRAK1. IRAK1 was down regulated in expanded IL-17 producing T cell in protein level.

real time PCR. miR-146a, miR-146b, miR-150, and miR155 were expressed intensely in RA in comparison to OA. There was a significant difference between RA and OA. The expression of miR-146a and miR-146b tended to increase with high disease activity, which was consistent with previous reports[24,25]. In particular, miR-150 was highly up regulated in the synovium of patients RA7, RA10 and RA11, (Figure 3A). Patient RA7 and RA11 were poor controlled with severe joint destruction. Patient RA10 had long disease duration subsequently severe joint destruction (Figure 3B). The disease activity in the synovium was analyzed histologically using IL-17 immunohistochemistry. The synovium with high expression of miR-146a, miR-146b, miR-150 and miR-155 showed vigorous proliferation of synovial cells and infiltration of inflammatory cells and abundant IL-17 positive cells. The analysis of the synovium from $\mathrm{RA}$ and OA patients revealed that miR-146a/b, miR-150 and miR-155 were highly expressed in RA synovium with hyperplasia and infiltration of inflammatory cells including Th17 producing cells in poorly controlled patients with severe joint destruction (Figure 4A).

\section{MiR-146a expressed in IL-17 producing cells}

MiR-146a was previuosly reported to be expressed in the $\mathrm{T}$ cells in the RA synovium [25]. We therefore confirmed whether miR-146a expressed in the IL-17 producing $\mathrm{T}$ cells using the double staining of in situ hybridization and immunohistochemistry of IL-17. MiR146a expression was mainly observed in the superficial and sublining layers as previuosly described [25]. In addition, IL-17 was seen in the RA synovium, while it was not seed in OA synovium. Double staining revealed that miR-146 + cells merged IL-17, thus indicating miR$146 \mathrm{a}$ to be expressed in $\mathrm{IL}-17$ producing $\mathrm{T}$ cells (Figure 4B).

\section{Discussion}

Recently, a potential link between miRNA and several human diseases has been revealed. For example, the expression of let-7 has been shown to be lower in lung cancer tissue than in normal lung tissue, and such down-regulation may promote high levels of expression of the Ras gene [30]. In addition, the expression of miR143 and miR-145 is reduced in colon cancer tissue. Evidence of miRNA function in conditions such as leukemia, viral infection, and DiGeorge syndrome has been reported [31,32]. Recent reports have suggested that several miRNA might participate in the pathogenesis of RA [21,24-26].

miRNAs have been investigated because of their potential clinical application for therapeutic methods. Therapeutic trials aimed at silencing miRNA in vivo have been conducted [32,33]. Tazawa et al. demonstrated that 


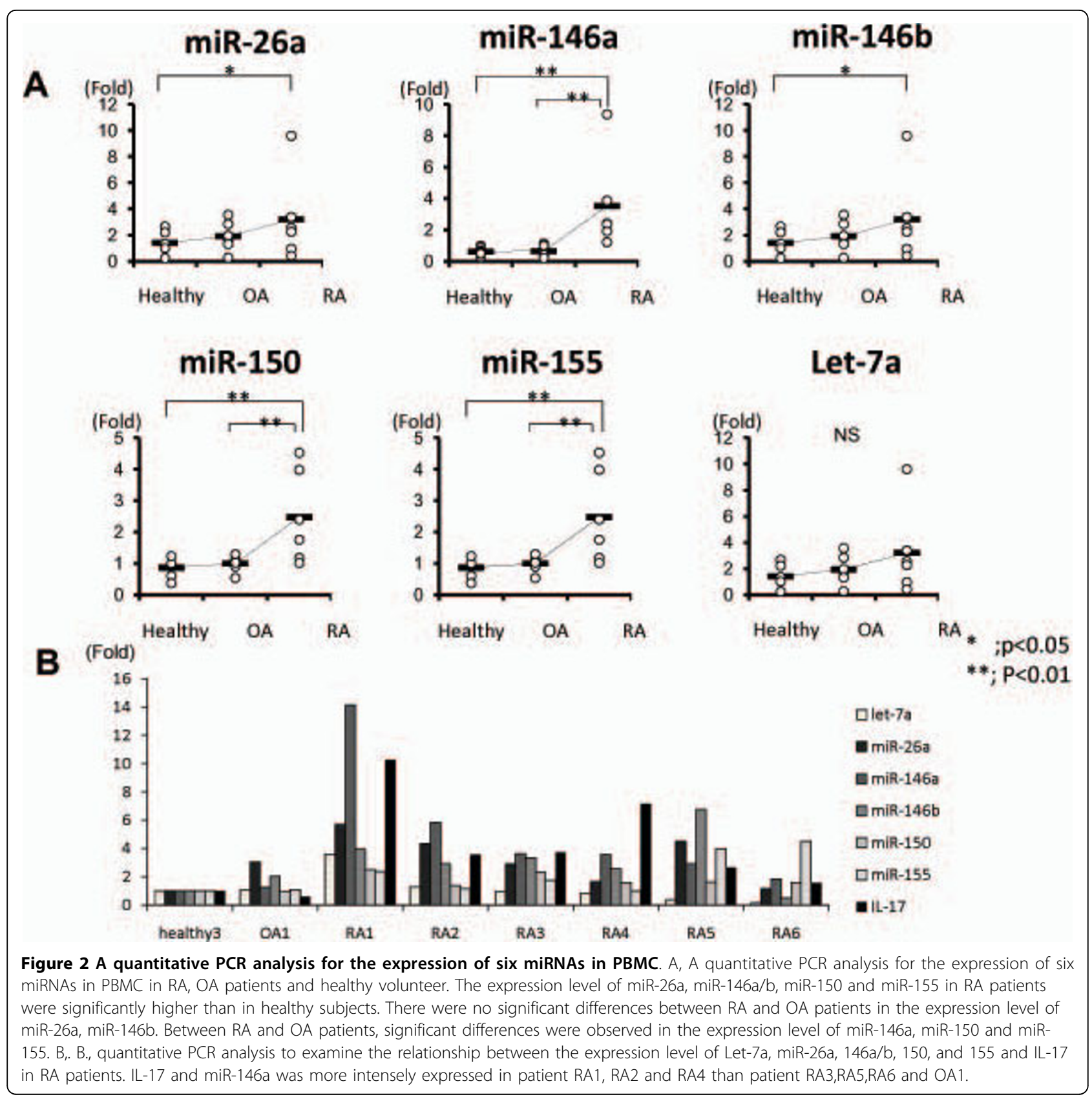

miR-34a is down-regulated in human colon cancer, and that tumor growth in mice is significantly inhibited by the local injection of synthetic double stranded miR-34a in vivo [34]. The intra-articular injection of double stranded miR-15a successfully induced cell apoptosis by inhibiting the translation of BCL2 protein in the synovium in arthritic mice. This suggested that the intraarticular injection of synthetic miRNAs can regulate the endogenous miRNAs in arthritic synovia [35]. The discovery of a new lineage of CD4+ effecter T helper (Th) cells that selectively produce IL-17 in mice has provided exciting new insights into immune regulation, host defense, and the pathogenesis of autoimmune and other chronic inflammatory disorders. Although IL-17 plays a crucial role in RA pathogenesis, the differentiation mechanism of human Th17 cells from CD4+ T cells is unclear. MiRNAs are reported to be a important factor in the differentiation of $\mathrm{T}$ cells [36]. Therefore, identification of miRNAs in Th17 cell differentiation could elucidate a new mechanism of RA pathogenesis, subsequently lead a novel therapeutic approach to the RA. In the current study, IL-17 producing T cells were expanded from PBMCs from healthy volunteers and the expression pattern of miRNAs in the differentiation of IL-17 producing 

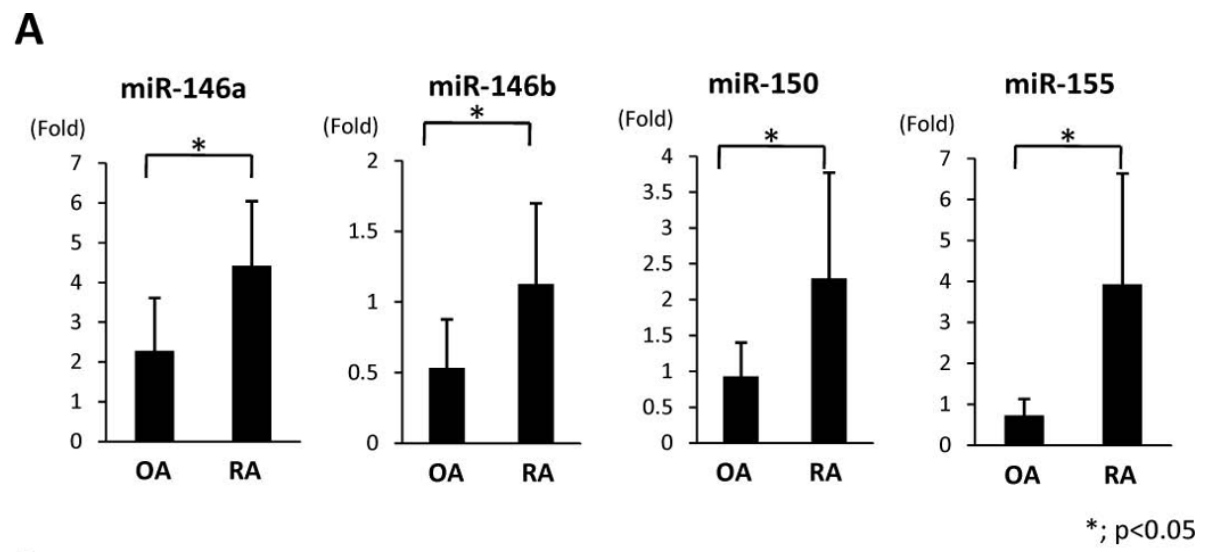

B

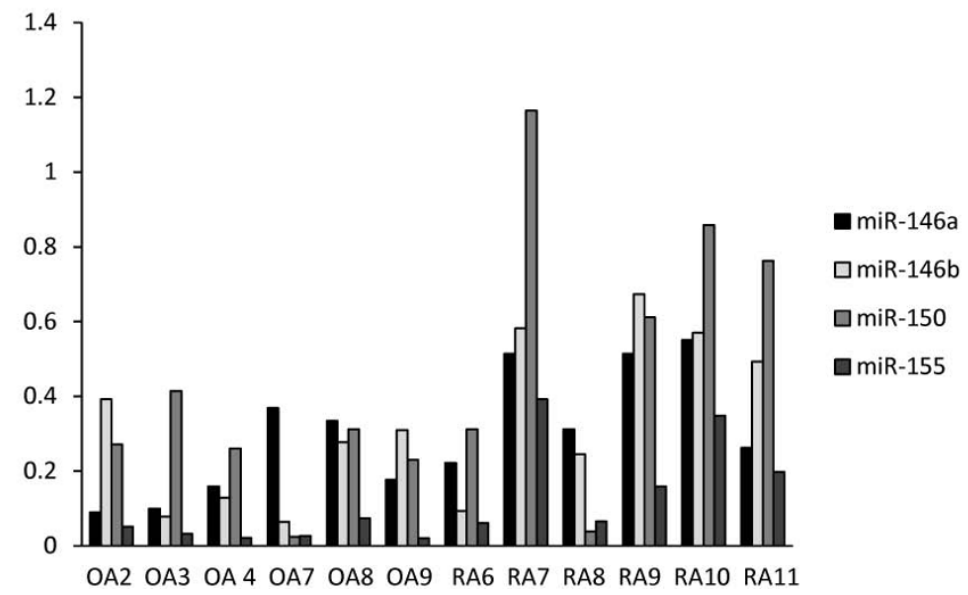

Figure 3 A quantitative PCR analysis for the expression of miRNAs in synovium. A, A quantitative PCR analysis for the expression level of miR-146a/b, miR-150, and miR-155 in synovium of RA and OA patients. All miRNAs were intensely expressed in RA synovium in comparison to OA. B, miR-146a and miR-146b tended to be express intensely in high disease activity. miR-150 was highly up regulated in synovium in patients RA7, RA10 and RA11.

cells was analyzed by using a Microarray analysis. This demonstrated that let-7a, miR-26a, 146a,b, 150, and 155 were significantly upregulated in the differentiation of IL-17 producing cells. There are several reports about Foxp3, ROR $\gamma \mathrm{t}$, IRAK1 and SOCS1in the differentiation of IL-17 producing T cells. Foxp3 is the transcription factor controlling regulatory $\mathrm{T}$ cell development[37], while, $\mathrm{ROR} \gamma \mathrm{t}$ is the master regulator that directs the differentiation program of Th17 cells [38]. The expression level of ROR $\gamma \mathrm{t}$ in expanded IL-17 producing T cells was significantly higher than in non-expanded cells, while Foxp3 was expressed more strongly in non-expanded cells in comparison to expanded cells, indicating that the IL-17 producing $\mathrm{T}$ cells were expanded. IRAK1 and SOCS1 not only play a crucial role in Th17 cell differentiation, but also are regulated by $\mathrm{miR}-146 \mathrm{a} / \mathrm{b}$ and $\mathrm{miR}-155$ respectively $[39,40]$. In the current series, the expression level of SOCS1 in expanded IL-17 producing T cells was significantly higher than in non-expanded cells. There was no significant difference in the expression level of
IRAK1 between the expanded and non expanded cells at the mRNA level. However IRAK1 protein was decreased in the expanded cells, which suggested miR-146a/b might inhibit the translation to IRAK1 protein from mRNA.

MiR-146a was expressed intensely with IL-17 expression in PBMC from the patients with early stage of RA and high disease activity. miR-146a/b was associated with high disease activity, and miR-150 was intensely expressed in the patients with severe joint destruction. MiR-150 has not been associated with the high expression of miR-146 and miR-155 in PBMC and synovium of RA in previous reports [24-26]. MiR-150 might also play a role in RA pathogenesis. The expression of miR146a and IL-17 was high in PBMC in patients with low score of Larsen grade and short disease duration in the current series. A patient with a high score of Larsen grade and long disease duration showed a low expression level of miR-146a, while that of miR-150 was high. Therefore, the high expression of miR-146a in PBMC was strongly associated with IL-17 expression, especially 


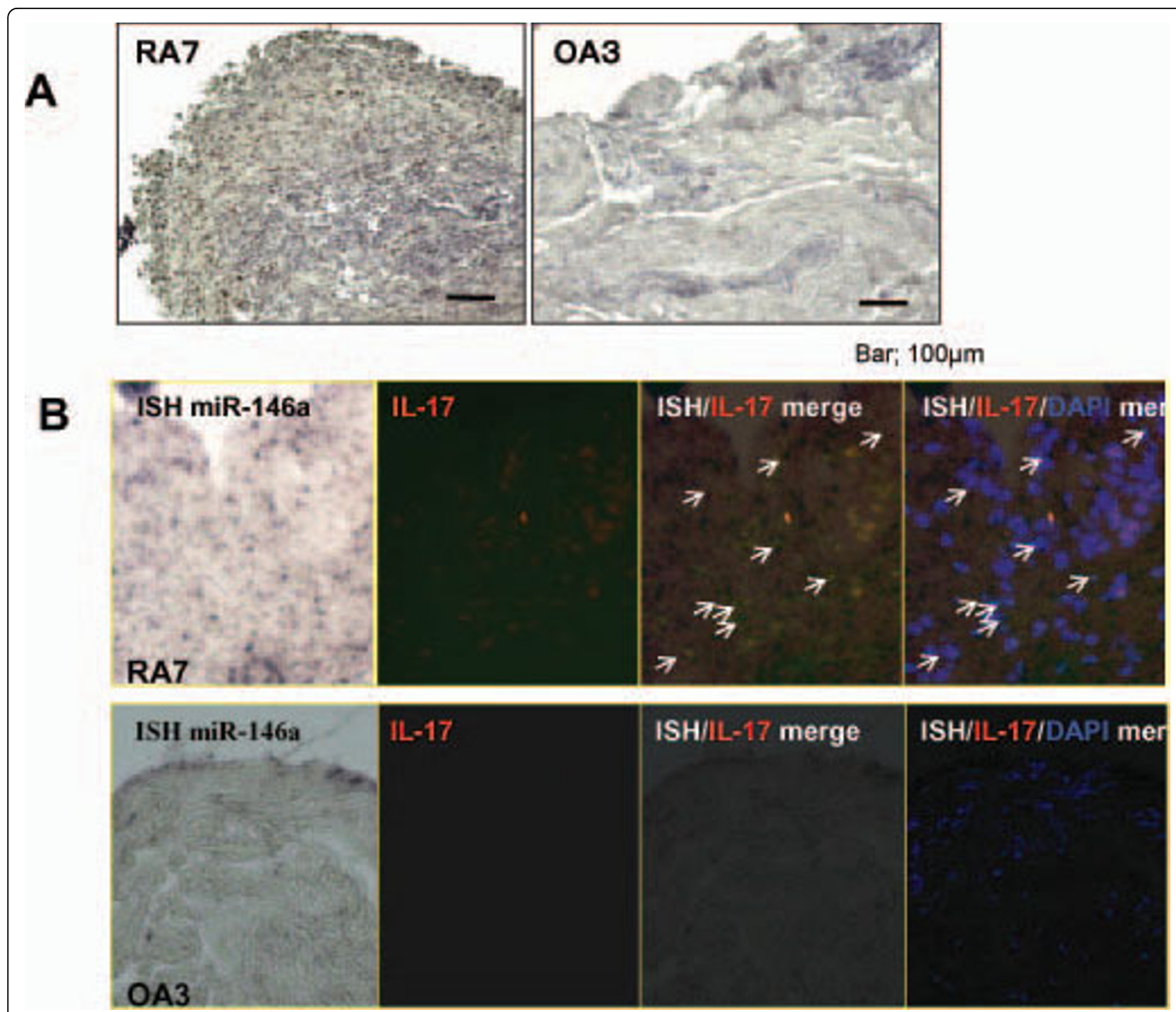

Figure 4 Immunohistochemistry and double staining combining in situ hybridization. A, Representative histology of RA and OA by immunohistochemistry of IL-17. RA synovium with high expression level of miR-146a/b, miR-150 and miR-155 demonstrated amount IL-17 positive cells in hyperplasia synovium while OA synovium had few IL-17 positive cells in the fibrous tissue. Original magnification 100x. Bar indicates $100 \mu \mathrm{m}$. B, Double staining for the in situ hybridization and immunohistochemistry of rheumatoid arthritis (RA) and osteoarthritis synovial tissue. In situ hybridization (ISH) for mature microRNA146-a (miR-146a) and immunohistochemistry with IL-17 antibodies were performed on synovial tissue specimens obtained from patient RA7 and OA3. Mature miR-146a was expressed in the cells of the superficial and sublining layers, thus including IL-17 positive cells. The arrows in the merged images indicate the cells expressing miR-146a and IL-17 antibody. Staining of the tissue sections with 4, 6-diamidino-2- phenylindole (DAPI) is shown at the right. (Original magnification X200).

at the early stage of RA. Severe joint destruction with high disease activity was associated with the expression of miR-150 in the synovium. The number of patients in the current study was small, therefore, further examination is necessary to clarify the relationship between these miRNAs and disease activity, including the expression level of IL-17. Our results revealed miR-146a to be expressed in the IL-17 producing T cells. In a previous report, accumulated $\mathrm{CD} 3+\mathrm{T}$ cells were observed to express miR-146, thereby suggesting that miR-146 might play a role in the persistent inflammation in RA via a $\mathrm{T}$ cell network, which strongly supports that miR-146a thus expressed in Th17 cells [25].

The current results suggested that miR-146a/b, miR150 and miR-155 might play a role in IL-17 producing $T$ cells differentiation and these miRNAs were expressed intensely in the PBMC and synovium in RA patients in comparison to OA patients and healthy subjects. In addition, the miR-146a expression in the IL-17 producing $\mathrm{T}$ cells of the RA synovium was confirmed. In the 
RA patients there is no report that analyzes miRNAs associated with IL-17 producing T cells. Changsheng Du et al. reported that miR-326 regulates Th-17 differentiation and associated with the pathogenesis of multiple sclerosis[27]. These evidence suggested that the function and analysis on the differentiation of IL-17 producing $\mathrm{T}$ cells is not simple, and perhaps they were depending on the disease variety, disease progression degree and the disease stage. Indeed, previous reports demonstrated that $\mathrm{miR}-146 \mathrm{a} / \mathrm{b}, \mathrm{miR}-150$ and $\mathrm{miR}-155$ are expressed in PBMC or synovium in RA patients, which might include miRNAs which are expressed in IL-17 producing $\mathrm{T}$ cells. However, the function of these miRNAs in the differentiation of IL-17 producing T cells was not elucidated in the present study. Several target genes of these 6 miRNAs were validated[30,40-53] (Table 3). The predicted target genes for miRNAs are estimated to range between one and several hundred, therefore, other target genes might play a role in the differentiation of IL-17 producing cells as well as the validated target genes. Further examination is needed to elucidate the function of these miRNAs including the determination of their target genes, which could lead to the development of novel therapeutic strategies for the treatment RA.

\section{Conclusions}

These results indicated that $\mathrm{miR}-146 \mathrm{a} / \mathrm{b}, \mathrm{miR}-150$ and miR-155 were associated with IL-17 expression in the PBMC and synovium in the RA patients, especially expression of miR-146a in IL-17 producing cells was comfirmed. Their altered expression in the stage and activity of RA suggested that they might play a role in the pathogenesis of RA via IL-17 expression. In addition, our results should be developed the excessive analysis of the function of these miRNAs in the RA to lead the novel treatment.

\section{Table 3 Validated target genes of 6 miRNAs}

\begin{tabular}{lll}
\hline miRNA & Targets & Referances \\
\hline let7a & Lin-41, Hbl-1, RAS, TRIM71 & {$[41],[42],[43],[30]$,} \\
& & {$[44]$} \\
miR-26a & Ezh2, GSK-3ß囚 & {$[45],[46]$} \\
miR-146a/ & TRAF6, IRAK1,IRAK2 & {$[47],[48]$} \\
b & & \\
miR-150 & c-Myb & {$[49]$} \\
miR-155 & FADD, IKK, Ripk1, TAB2, PU.1, SOCS1, & {$[50],[51],[52],[40]$,} \\
& AID & {$[53]$} \\
\hline
\end{tabular}

TRIM71: tripartite motif-containing 71;Ezh2: Enhancer of Zeste homolong2;

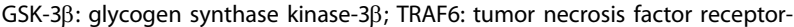
associated factor 6; IRAK-1: Interleukin-1 receptor-associated kinase 1; IRAK-2: Interleukin-1 receptor-associated kinase 2;FADD: Fas-associated death domain protein; IKK: I $\kappa$ B kinase; Ripk1: receptor interacting serine-threonine kinase 1; SOCS-1: suppressor of cytokine signaling 1; AID: activation-induced cytidine deaminase;

\section{Abbreviations}

RA: rheumatoid arthritis; OA: osteoarthritis; K/L: Kellgren/Lawrence; CRP: C-reactive protein; ESR: erythrocyte sediment rate; RF: rheumatoid factor; MTX: methotrexate; NSAIDs: nonsteroidal anti-inflammatory drugs; ROR $\gamma$ :

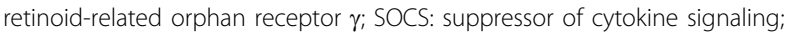
IRAK1: IL-1 receptor-associated kinase 1.

\section{Acknowledgements}

The authors thank Professor Michihiro Hide for permission to use the instruments and Ms Kaori Ishii for technical support with auto MACS. (Department of Dermatology, Graduate School of Biomedical Sciences, Hiroshima University, Japan).

\section{Authors' contributions}

TN and TN designed this study. TN conducted all experiments and drafted manuscript. MD, OA and OS collected patients' samples. NA and MI provided clinical insights and edited manuscript. TN assisted with statistical evaluations. $\mathrm{MO}$ conceived of the study, assisted in designing the study, and edited the manuscript. All authors read and approved the final manuscript.

\section{Competing interests}

The authors declare that they have no competing interests.

Received: 24 May 2010 Accepted: 15 September 2010

Published: 15 September 2010

\section{References}

1. Gardner DL: In: Pathological basis of the connective tissue diseases. London:Edward Arnold 1992, 444-526, Rheumatoid arthritis: cell and tissue pathology.

2. Harrington LE, Hatton RD, Mangan PR, Turner $H$, Murphy $T L$, Murphy KM, Weaver CT: Interleukin 17-producing CD4+ effector T cells develop via a lineage distinct from the $\mathrm{T}$ helper type 1 and 2 lineages. Nat Immunol 2005, 6:1123-1132.

3. Park $H$, Li Z, Yang XO, Chang $S H$, Nurieva $R$, Wang $Y H$, Wang $Y$, Hood L, Zhu Z, Tian Q, et al: A distinct lineage of CD4 T cells regulates tissue inflammation by producing interleukin 17. Nat Immunol 2005 6:1133-1141

4. Spriggs MK: Interleukin-17 and its receptor. J Clin Immunol 1997 17:366-369.

5. Acosta-Rodriguez EV, Napoletani G, Lanzavecchia A, Sallusto F: Interleukins $1 \beta$ and 6 but not transforming growth factor- $\beta$ are essential for the differentiation of interleukin 17-producing human T helper cells. Nat Immunol 2007, 8:942-949.

6. Chen Z, Tato CM, Muul L, Laurence A, O'Shea JJ: Distinct regulation of interleukin-17 in human T helper lymphocytes. Arthritis Rheum 2007, 56:2936-2946.

7. Wilson NJ, Boniface K, Chan JR, McKenzie B, Blumenschein WM, Mattson JD, Basham B, Smith K, Chen T, Morel F, et al: Development, cytokine profile and function of human interleukin 17-producing helper T cells. Nat Immunol 2007, 8:950-957.

8. van Beelen AJ, Zelinkova Z, Taanman-Kueter EW, Muller FJ, Hommes DW, Zaat SAJ, Kapsenberg ML, de Jong EC: Stimulation of the intracellular bacterial sensor NOD2 programs dendritic cells to promote interleukin17 production in human memory T cells. Immunity 2007, 27:1-10.

9. Sato K, Takayanagi H: Osteoclasts, rheumatoid arthritis, and osteoimmunology. Curr Opin Rheumatol 2006, 18:419-426.

10. Takayanagi $\mathrm{H}$ : Osteoimmunology: shared mechanisms and crosstalk between the immune and bone systems. Nat Rev Immunol 2007, 7:292-304.

11. Kojiro S: Th17 cells and rheumatoid arthritis-from the standpoint of osteoclast differentiation. Allergology International 2008, 57:109-114.

12. Chabaud M, Durand JM, Buchs N, Fossiez F, Page G, Frappart L, Miossec P. Human interleukin-17: a T cell-derived proinflammatory cytokine produced by the rheumatoid synovium. Arthritis Rheum 1999, 42:963-970.

13. Kotake S, Udagawa N, Takahashi N, Matsuzaki K, Itoh K, Ishiyama S, Saito S, Inoue K, Kamatani N, Matthew T: IL-17 in synovial fluids from patients with rheumatoid arthritis is a potent stimulator of osteoclastogenesis. J Clin Invest 1999, 103:1345-1352.

14. Ziolkowska M, Koc A, Luszczykiewics G, Ksiezopolska-Pietrzak K, Klimczak E, Chwalinska-Sadowska H, Malinski W: High levels of IL-17 in rheumatoid 
arthritis patients: IL-15 triggers in vitro IL-17production via cyclosporin A-sensitive mechanism. J Immunol 2000, 164:2832-2838.

15. Ambros V: The functions of animal microRNAs. Nature 2004, 431:350-355

16. Bartel DP, Chen CZ: MicroRNAs: genomics, biogenesis, mechanism, andfunction. Cell 2004, 116:281-297.

17. Farh KK, Grimson A, Jan C, Lewis BP, Johnson WK, Lim LP, Burge $C B$, Bartel DP: The widespread impact of mammalian microRNAs on mRNArepression and evolution. Science 2005, 310:1817-1821.

18. Denli AM, Tops BB, Plasterk RH, Ketting RF, Hannon GJ: Processing of primary microRNAs by the Microprocessor complex. Nature 2004, 432:231-235.

19. Gregory RI, Yan KP, Amuthan G, Chendrimada T, Doratotaj B, Cooch N Shiekhattar R: The Microprocessor complex mediates the genesis of microRNAs. Nature 2004, 432:235-240.

20. Lee Y, Ahn C, Han J, Choi H, Kim J, Yim J, Lee J, Provost P, Redmark O, Kim S, et al: The nuclear RNase III Drosha initiates microRNA processing Nature 2003, 425:415-419.

21. Chendrimada TP, Gregory RI, Kumaraswamy E, Norman J, Cooch N, Nishikura K, Shiekhattar R: TRBP recruits the Dicer complex toAgo2 for microRNA processing and gene silencing. Nature 2005, 436:740-744

22. Calin GA, Sevignani C, Dumitru CD, Hyslop T, Noch E, Yendamuri $S$, Shimizu M, Rattan S, Bullrich F, Negrini M: Human microRNA genes are frequently located at fragile sites and genomic regions involved in cancers. Proc Natl Acad Sci USA 2004, 101:2999-3004

23. Lecellier $\mathrm{CH}$, Dunoyer $\mathrm{P}$, Arar K, Lehmann-Che J, Eyquem S, Himber $\mathrm{C}$, Saib A, Voinnet O: A cellular microRNA mediates antiviral defense in human cells. Science 2005, 308:557-560.

24. Stanczyk J, Pedrioli DM, Brentano F, Sanchez-Pernaute O, Kolling C, Gay RE, Detmar M, Steffen Gay, Kyburz D: Altered expression of microRNA in synovial fibroblasts and synovial tissue in rheumatoid arthritis. Arthritis Rheum 2008, 58:1001-1009.

25. Nakasa T, Miyaki S, Okubo A, Hashimoto M, Nishida K, Ochi M: Expression of microRNA-146 in rheumatoid arthritis synovial tissue. Arthritis Rheum 2008, 58:1284-1292.

26. Pauley KM, Satoh M, Chan AL, Bubb MR, Reeves WH, Chan EK: Upregulated miR-146a expression in peripheral blood mononuclear cells from rheumatoid arthritis patients. Arthritis Res Ther 2008, 10:R101.

27. Changsheng D, Chang L, Jiuhong K, Guixian Z, Zhiqiang Y, Shichao H, Zhenxin L, Zhiiying W, Gang P: MicroRNA-326 regulates Th-17 differentiation and associated with the pathogenesis of multiple sclerosis. Nat Immunol 2009, 10:1252-1259.

28. Arnett FC, Edworthy SM, Bloch DA, McShane DJ, Fries JF, Cooper NS: The American Rheumatism Association 1987 revised criteria for the classification of rheumatoid arthritis. Arthritis Rheum 1988, 31:315-324.

29. Amadi-obi A, Yu CR, Liu X, Mahdi RM, Clarke GL, Nussenblatt RB, Gery L, Lee YS, Egwuagu CE: Th17 cells contribute to uveits and scleritis and are expanded by IL-2 and inhibited by IL-27/STAT1. Nat Med 2007, 13:711-718.

30. Johnson SM, Grosshans H, Shingara J, Byrom M, Jarvis R, Cheng A Emmanuel L, Reinert KL, Brown D, Slack FJ: RAS is regulated by the let-7 microRNA family. Cell 2005, 120:635-647.

31. Michael MZ, O'Conner SM, van Holst Pellekaan NG, Young GP, James RJ: Reduced accumulation of specific microRNAs in colorectal neoplasia. Mol Cancer Res 2003, 1:882-891.

32. Krutzfeldt J, Rajewsky N, Braich R, Rajeev KG, Tuschl T, Manoharan M: Silencing of microRNAs in vivo with 'antagomirs'. Nature 2005, 438:685-689.

33. Yang B, Lin H, Xiao J, Lu Y, Luo X, Li B, Zhang Y, Xu C, Bai Y, Wang H: The musclespecific microRNA miR-1 regulates cardiac arrhythmogenic potential by targeting GJA1 and KCNJ2. Nat Med 2007, 13:486-491.

34. Tazawa H, Tsuchiya N, Izumiya M, Nakagama H: Tumor-suppressive miR34a induces senescence-like growth arrest through modulation of the E2F pathway in human colon cancer cells. Proc Natl Acad Sci USA 2007, 104:15472-15477.

35. Nagata $Y$, Nakasa T, Mochizuki Y, Ishikawa M, Miyaki S, Shibuya $H$, Yamasaki K, Adachi N, Asahara H, Mitsuo Ochi: Induction of apoptosis in the synovium of mice with autoantibody-mediated arthritis by the intraarticular injection of double-stranded MicroRNA-15a. Arthritis Rheum 2009, 60:2677-2683.

36. Turner $\mathrm{M}$, Vigorito $\mathrm{E}$ : Regulation of $\mathrm{B}$ - and T-cell differentiation by asingle microRNA. Biochem Soc Trans 2008, 36:532-533.
37. Hori S, Nomura T, Sakaguchi S: Control of regulatory T cell development by the transcription factor Foxp3. Science 2003, 299:1057-1061.

38. Ivanov II, Mackenzie BS, Zhou L, Tadokoro CE, Lepelley A, Lafaille JJ, Cua DJ, Littman DR: The orphan nuclear receptor ROR $\gamma$ t directs the differentiation program of proinflammatory IL-17+ T helper cells. Cell 2006, 126:1121-1131

39. Yoshimura A, Naka T, Kubo M: SOCS proteins,cytokine signaling and immune regulation. Nat Reu Immunol 2007, 7(6):454-465.

40. Li-Fan L, To-Ha T, Dinis PC, Ashutosh C, Kubo M, Tanaka K, Loeb GB, Lee H, Yoshimura A, Rajewsky K, et al: Foxp3-Dependent MicroRNA155 Confers Competitive Fitness to Regulatory T Cells by Targeting SOCS1 Protein. Immunity 2009, 30:80-91.

41. Slack FJ, Basson M, Liu Z, Ambros V, Horvitz HR, Ruvkun G: The lin-41 RBCC gene acts in the $C$. elegans heterochronic pathway between the let- 7 regulatory RNA and the LIN-29 transcription factor. Mol Cell 2000, 5:659-669.

42. Abrahante JE, Daul AL, Li M, Volk ML, Tennessen JM, Miller EA, Rougvie AE The Caenorhabditis elegans hunchback-like gene lin-57/hbl-1 controls developmental time and is regulated by microRNAs. Dev Cell 2003, 4:625-637.

43. Lin SY, Johnson SM, Abraham M, Vella MC, Pasquinelli A, Gamberi C, Gottlieb E, Slack FJ: The C. elegans hunchback homolog, hbl-1, controls temporal patterning and is a probable microRNA target. Dev Cell 2003, 4:639-650

44. You-Chin L, Li-Ching H, Ming-Wei K, John Y, Huan-Hsien K, Wan-Lin L, RueyJen L, Alice LY, Wen-Hsiung L: Human TRIM71 and Its Nematode Homologue Are Targets of let-7 MicroRNA and Its Zebrafish Orthologue Is Essential for Development. Mol Biol Evol 2007, 24(11):2525-2534.

45. Chung FW, Ross LT: MicroRNA-26a Targets the Histone Methyltransferase Enhancer of Zeste homolog 2 during Myogenesis. J Biol chem 2008, 283(15):9836-9843.

46. Junaith SM, Michael AL, Aladin MB: Mechanical Stretch Upregulates MicroRNA-26a and Induces Human Airway Smooth Muscle Hypertrophy by Suppressing Glycogen Synthase Kinase-33. J Biol chem 2010.

47. Taganov KD, Boldin MP, Chang KJ, Baltimore D: NFkappaB dependent induction of microRNA miR-146, an inhibitor targeted to signaling proteins of innate immune responses. Proc Natl Acad Sci USA 2008, 103:12481-12486.

48. Hou J, Wang P, Lin L, Liu X, Ma F, An H, Wang Z, Cao X: MicroRNA-146a feedback inhibits RIG-I-dependent type I IFN production in macrophages by targeting TRAF6, IRAK1, and IRAK2. J Immunol 2009, 183:2150-2158.

49. Barroga Charlene F, Pham Hang, Kaushansky Kenneth: Thrombopoietin regulates c-Myb expression by modulating micro RNA 150 expression. Experimental Hematology 2008, 36:1585-1592.

50. Tili E, Michaille JJ, Cimino A, Costinean S, Dumitru CD, Adair B, Fabbri M, Alder H, Liu CG, Calin GA, et al: Modulation of miR-155 and miR-125b levels following lipopolysaccharide/TNF-alpha stimulation and their possible roles in regulating the response to endotoxin shock. I Immunol 2007, 179:5082-5089.

51. Ceppi M, Pereira PM, Dunand-Sauthier I, Barras E, Reith W, Santos MA, Pierre P: MicroRNA-155 modulates the interleukin-1 signaling pathway in activated human monocyte- derived dendritic cells. Proc Natl Acad SCi USA 2009, 106:2735-2740.

52. Martinez-Nunez RT, Louafi F, Friedmann PS, Sanchez-Elsner T: MicroRNA155 modulates the pathogen binding ability of dendritic cells (DCs) by down-regulation of DC-specific intercellular adhesion molecule-3 grabbing non-integrin (DCSIGN). J Biol Chem 2009, 284:16334-16342.

53. Teng G, Hakimpour P, Landgraf P, Rice A, Tuschl T, Casellas R, Papavasiliou FN: MicroRNA-155 is a negative regulator of activationinduced cytidine deaminase. Immunity 2008, 28:621-629.

\section{Pre-publication history}

The pre-publication history for this paper can be accessed here: http://www.biomedcentral.com/1471-2474/11/209/prepub

doi:10.1186/1471-2474-11-209

Cite this article as: Niimoto et al:: MicroRNA-146a expresses in interleukin-17 producing T cells in rheumatoid arthritis patients. $B M C$ Musculoskeletal Disorders 2010 11:209. 